\title{
Learning from failure: are practitioner researchers the answer when conducting research on sensitive topics with vulnerable children and young people?
}

\author{
Nina Vaswani \\ Research Fellow, Centre for Youth and Criminal Justice, University of Strathclyde
}

Research that is concerned with sensitive topics such as loss and bereavement can be ethically and methodologically challenging at the best of times (Cook, 1995; Dyregrov, 2004; Stroebe, Stroebe, \& Schut, 2003). As Dyregrov observes: "It is well documented that research proposals in this field are much more likely to be rejected by International Review Boards compared to other proposals..." (2004, p. 391). Concerns include: the risk of causing additional distress or retraumatisation for participants (Buckle, Dwyer, \& Jackson, 2010; Newman, Risch, \& Kassam-Adams, 2006; Rosenblatt, 1995), the potential for secondary or vicarious trauma on behalf of the researcher (Dickson-Swift, James, Kippen, \& Liamputtong, 2007; Newman et al., 2006; Rowling, 1999), and the fact that the universal human experiences of loss and death can colour the perspective of the supposedly 'objective' researcher (Rowling, 1999; Woodthorpe, 2009). These challenges are amplified when conducting loss and bereavement research with children and young people. Throw in a further element of vulnerability, such as children who are in the care of the authorities (Fargas-Malet, McSherry, Larkin, \& Robinson, 2010; Powell \& Smith, 2009) and these issues take on a different magnitude all together.

It should perhaps therefore not have been surprising that my attempt to conduct a small-scale qualitative study with young people in residential care about their experiences of loss and grief did not manage to surmount these challenges, and ultimately proved unsuccessful. I spent some time pondering on this outcome and, not willing to admit defeat, have documented my experiences in this paper. By providing a rare reflection on a research 'failure' (Payne, 2011), and by illuminating my methodological issues and dilemmas (Connolly \& Reilly, 2007), my paper is of significance to students, practitioners and researchers alike. First, I summarise the key research literature on conducting ethical research with children and document the shifting roles of researcher, practitioner and participant. Next, I revisit the study to reflect on the ethical and methodological choices that I made and the challenges that I encountered. In mapping the research literature to my experiences, I conclude that a 
methodological approach incorporating an element of practitioner research may have overcome many of these barriers.

\section{Topsy Turvy Roles in Research Today: Children as Experts, Practitioners as Researchers and Researchers as Facilitators?}

Modern qualitative inquiry, with its emphasis on exploring meanings and experiences (Buckle et al., 2010; Hadjistavropoulos \& Smythe, 2001) coupled with a lack of hard and fast rules towards data collection and analysis (Patton, 2002), frequently requires the jumbling of traditional research and participant roles.

\section{Children as Experts}

The way in which children are perceived as research participants has evolved, from a time when children's views were not considered important, through the conception of children as passive subjects from whom data could be gathered (Einarsdottir, 2005; Powell \& Smith, 2009). Nowadays children are viewed as active and engaged research participants, experts in their own world and important in helping to create new knowledge. Indeed children's right to participate, to have their voices heard and to have influence over their own lives is enshrined in the United Nations Convention on the Rights of the Child (Shaw, Brady, \& Davey, 2011).

However, understanding this is not enough to ensure that research with young people is meaningful and accessible. Children do not identify, construct and articulate their world in the same way as adults and it is not always sufficient to simply adapt ethical processes or research methods that are used with adults (Kirk, 2007; Punch, 2002). For children to be able to share their expertise innovative and child-centred research designs and methods may be needed (Einarsdottir, 2005; Morris, Hegarty, \& Humphreys, 2012; Punch, 2002).

Similarly, there are some ethical considerations that are especially pertinent when conducting research with children, vulnerable participants or on sensitive issues. These include access and gatekeepers (Aldridge, 2012; Fargas-Malet et al., 2010; Horowitz, Ladden, \& Moriarty, 2002; Punch, 2002); informed consent (Fargas-Malet et al., 2010; Kirk, 2007; Morris et al., 2012; Wiles, Crow, Charles, \& Heath, 2007); power imbalances (Morris et al., 2012; Powell \& Smith, 2009); relationships and rapport (Atkinson, 2005; Dickson-Swift et al., 2007; Punch, 2002); confidentiality and anonymity 
(Morris et al., 2012; Phelan \& Kinsella, 2013; Rowling, 1999) and minimising distress (Kirk, 2007; Omerov, Steineck, Dyregrov, Runeson, \& Nyberg, 2014).

\section{Practitioners as Researchers}

With the increasing focus on evidence-informed practice and accountability in social work and related fields, generating more practitioner research is viewed as an important way to increase the quality and quantity of research (Shaw \& Lunt, 2012). Practitioner research is commonly described as research primarily conducted by professionals who are mainly engaged in practice (Uggerhøj, 2012). It is this definition that I have adopted for use in this paper, rather than simply research that is concerned with practice (practice research) or the broader empirical practice which incorporates these definitions and also refers to evidence-informed practice (Reid, 1994). The social work field has broadly accepted practitioner research as a valid form of inquiry (Atkinson, 2005; Shaw, 2005) that is instrumental in creating localised and small-scale change (Brydon-Miller \& Maguire, 2009) and as a core element of good social work practice (Shaw \& Lunt, 2012), although debates remain about whether it also constitutes good research. Historically, practitioner research has suffered from lower status (Dadds, 1998; Pain, 2011), a lack of methodological rigour (Atkinson \& Delamont, 1993); insufficient attention paid to existing theory and evidence (IRISS, 2013) and a focus on small-scale problem-solving (Groundwater-Smith \& Mockler, 2007; Pain, 2011) that, while important, has little to contribute to theory building (Dadds, 1998) or transformative change (Brydon-Miller \& Maguire, 2009).

Despite these issues, practitioner research is also documented as having a number of benefits, often associated with the 'insider' status of the 'researcher', such as access to participants (Coy, 2006), and a knowledge base that brings added insights and depth of understanding (Dwyer \& Buckle, 2009; Greene, 2014; Hodkinson, 2005). At the same time, practitioner research also faces logistical, ethical and methodological problems over and above that experienced in a typical research project. These include: a lack of time and capacity (Dadds, 1998; IRISS, 2013; Shaw \& Lunt, 2012); a lack of financial or other support (Dadds, 1998; Pain, 2011; Shaw \& Lunt, 2012), a need to develop research skills (Pain, 2011; Shaw \& Lunt, 2012), and limited opportunities for dissemination (IRISS, 2013; Mitchell, Lunt, \& Shaw, 2010). And while the insider role offers advantages, it also creates ethical challenges in itself, as the duality creates the potential for confusion (Coy, 2006; Dwyer \& Buckle, 2009; Pritchard, 2002); deep-rooted power differentials (Atkinson, 2005; Pain, 2011); the need to maintain critical distance 
(Appleby, 2013; Greene, 2014) and complications associated with anonymity and confidentiality (Pritchard, 2002; Shaw, 2005).

\section{Researchers as Facilitators}

With young people as experts and practitioners as researchers, what becomes the role of the academic researcher in modern qualitative inquiry? It would be remiss to dismiss the experience, skills, perspective, time and funding opportunities that come with years of academic study and thinking. Stoecker (1999) envisages three roles for academics, that of initiator, consultant and collaborator, suggesting that academics need to play more of a facilitating role, rather than a leading role in research. Furthermore, having an academic mentor has been identified as of value by practitioners (IRISS, 2013) and has been associated with successful completion of practitioner research and the establishment of collaborative relationships (Joubert \& Hocking, 2015).

In reflecting on my research for this paper, it became clear that there was only a partial subversion of roles. The project was one in which the children were experts, but where I, the researcher, retained a traditional role, and the practitioners remained practitioners, but upon whom I depended for the successful completion of the research project. The study did not set out to be a practitioner research project, so this in itself is unsurprising, but the following case study will suggest that a greater intermingling of research roles may have helped to overcome many of the challenges that I faced.

\section{A Picture of Loss: Exploring the Conceptualisation and Experiences of Loss among Young People in Care}

While loss and bereavement remain universal human experiences, research has emerged about the prevalence and nature of these experiences in vulnerable populations, such as my research with young people involved in offending (Vaswani, 2014) and young people looked after in care placements away from home (Brodzinsky, 2009; Courtney, 2000). Backgrounds characterised by neglect, abuse, addiction, mental illness, family breakdown and multiple disadvantage not only create an environment that is ripe for loss and bereavement (Vaswani, 2015), but also increase the likelihood that a young person will be looked after away from home (Hare \& Bullock, 2006).

Entering the care system may further compound these losses by severing bonds and attachments to people and places as well as creating a unique set of losses, such as loss of identity or 
loss of status (Brodzinsky, 2009; Vaswani, 2015). The nuances and complications of these more ambiguous losses means that the grief arising from involvement in the care system may be more difficult to resolve than other forms of loss (Brodzinsky, 2009; Courtney, 2000). The experience of loss, bereavement and grief in the looked after population is therefore substantial and wide-ranging, but there is little research documenting loss from a young person's perspective (Ribbens McCarthy, 2005) or in how the different types of loss are experienced.

\section{The Research}

In order to address these gaps I designed a small-scale qualitative study to explore with young people their conceptualisations of loss and grief and to document the extent and nature of their losses. Ten participants aged 12-17 who were currently living in a care placement away from home would be recruited to the study over a seven-month period. I planned to disseminate the findings among a variety of audiences, including: residential, social work and other related practitioners, academic audiences and young people with the aim of influencing both knowledge and practice.

I adopted a creative approach, in this case photography, to ensure that young people were active and engaged participants in the process (Aldridge, 2012; Allen, 2011; Einarsdottir, 2005). I also recruited a photographer to assist in the project and to give it authenticity and credibility among my adolescent participants. I asked the participants to create, or collate, photographs and images of people, places or objects that reminded them of the things that they missed in their lives. In conjunction with myself and the photographer, the young people were later supported to create a storyboard using their images, and the storyboard then formed the basis of a semi-structured interview about loss: with interviews focusing on the content of the photographs (who, what or where), their decision-making about which photos to use and how to display them (why) and the impact of creating, looking or thinking about the photo (how it made them feel).

The project was well received and generated interest among academic colleagues, practitioners, and from professional publications:

I wanted to know the timescales and visual storytelling you were going to use in the hope of using these images and designs as part of a possible feature when it is ready. (Journalist)

The project commenced early in 2015 and with the combined motivations of a new year and a new project, I embarked upon the project eagerly, with enthusiasm and only a little trepidation. Fast 
forward five months and, although my enthusiasm had not diminished, I was struck by a growing sense of unease that the project was not proceeding as planned. I was still grappling with various ethics committees and had not recruited a single participant to my study. Even by the end of the study I had only recruited a third of the sample that I needed, with one participant opting to withdraw during the creative phase.

\section{Ethical, Methodological and Practical Challenges}

From the outset it was clear that I needed to pay careful attention to the ethical and methodological issues arising from conducting such research with vulnerable young people. Yet, despite careful planning and adaptations, I encountered many of the issues highlighted in the literature. My experience of these ethical, methodological and practical challenges are presented in this paper.

Participatory and engaging methodologies.

For me, choosing the overarching methodology was a crucial decision. Photo-elicitation is a way of using photographs and images as a stimulus for discussion in a subsequent interview. The photograph is seen as an especially advantageous method of eliciting rich data because of the essence of the photograph itself (Collier, 1957) and its interaction with memory: "Photographs appear to capture the impossible: a person gone; an event past. That extraordinary sense of seeming to retrieve something that has disappeared belongs alone to the photograph, and it leads to deep and interesting talk" (Harper, 2002, p. 23).

Photo elicitation seemed to me to be an especially meaningful and appropriate method for exploring my research questions. Sifting through photographs of loved ones, or important times and places is a familiar activity that allows individuals to reflect and reminisce. Indeed, Riches and Dawson (1998) describe the role that photographs can play in the processing of grief among bereaved parents. It is also an engaging and creative method that appeals to children and young people of all ages and backgrounds (Cappello, 2005; Einarsdottir, 2005; Kolb, 2008). Photo-methods have been successfully used in research with very young children (Einarsdottir, 2005); young carers (Aldridge, 2012); children with disabilities (Phelan \& Kinsella, 2013); young migrants (Fassetta, 2016) and on sensitive topics such as the sexual culture of schools (Allen, 2011) and children with chronic health conditions (Close, 2007). 
The methodology was particularly appealing to adult practitioners and the ethical reviewers. The young people who participated also appeared to find the process meaningful:

Your research looks really interesting, I love the idea of using art and photography. I have at least one young person that I am working with that I think will be interested in being involved (third sector practitioner)

I quite like photography though...just being able to capture the moment, sometimes I care more about getting the photo than I do about the actual moment so I can look back on it and remember it (young person)

Yet the methodology itself proved cumbersome for both myself as a researcher, and for the practitioners whom I relied upon during the process. Firstly, photo-elicitation can be time-consuming and expensive (Bignante, 2010; Whiting, 2015). Some young people required support to take and develop their photos, a task which fell to the practitioners supporting them. While this was anticipated, and practitioners provided consent to confirm that they understood the expectations of them, the realities of day-to-day practice meant that this limited some of the data gathering that young people could do.

A practitioner research approach, with practitioners directly involved in the design and delivery of the research, rather than simply as an intermediary for my data collection, may have been able to better support young people. Although time, or rather a lack of it, is an often documented feature of practitioner research (Dadds, 1998; Shaw \& Lunt, 2012), practitioners (especially in residential childcare) do have regular contact with young people, and being formally involved in practitioner research may have given them the 'permission' needed to free up the necessary capacity.

Ethical approval.

Like many researchers conducting research on sensitive topics with children (Dyregrov, 2004; Powell \& Smith, 2009), I found getting ethical approval for my study somewhat problematic. Surprisingly my trouble was not at ethics committee level per se, indeed my encounters with various ethics committees found them to be very supportive. Some committees did put in an additional layer of checks, for example by inviting me to attend a meeting with the review board to discuss the project further, but gaining the approval of an ethics committee proved a fairly straightforward element of the research. 
What did prove challenging, however, was not only the sheer number of ethics committees, with their various protocols and procedures and forms, but also how to respond to a multitude of feedback that was, on occasion, conflicting. Obtaining consent from my own University's Ethics Committee was my first task, but this could not be arranged until I had received confirmation of my award. Despite a swift turnaround by the committee, this meant that I was well into month two of a twelve-month project before I had clearance to approach potential participants. Months two to four were spent raising awareness of the research project and contacting potential gatekeepers, and months three to six were spent negotiating with each potential organisations' own ethics procedures. All of the organisations that I approached gave their approval for me to conduct my study, but with the back and forth between committees to update on subsequent modifications, it was month six before I managed to recruit my first participant.

With the acuity of hindsight, the project design was unlikely to be feasible within a 12-month timeframe. Practitioner research would, of course, not have been exempt from ethical scrutiny and review, indeed practitioner researchers have described the process of obtaining ethical clearance as frustrating and time consuming (IRISS, 2013). However, their position as 'insider' may have provided the opportunity to informally gauge interest among potential participants prior to ethical approval and they may already have been known by members of the ethics committee, providing a comforting level of familiarity and trust.

Access and gatekeepers.

Gaining access to participants is more complex when they are young or vulnerable, not only are there obstacles to identifying participants (Aldridge, 2012; Horowitz et al., 2002), but recruitment is often via adult gatekeepers (Fargas-Malet et al., 2010; Punch, 2002) which can cause barriers and delays. Gatekeepers are important for the protection of children given the power differential between adult researchers and child participants (Horowitz et al., 2002) but, depending on how this authority is applied, this in itself may not address the power imbalance created by adult decision-making in the lives of children. Indeed the concerns (valid or otherwise) of gatekeepers can exclude children from research and, at times, fail to uphold their participation rights (Kirk, 2007; Powell \& Smith, 2009). For example, the large number of adult gatekeepers involved in the lives of children in care can make access highly complex and disenfranchise those who are often already marginalised (Fargas-Malet et al., 2010; 
Powell \& Smith, 2009). Thus researchers need to also spend time building relationships with gatekeepers (Powell \& Smith, 2009; Punch, 2002) and in gaining the trust of both gatekeepers and participants (Emmel, Hughes, Greenhalgh, \& Sales, 2007).

I encountered numerous layers of gatekeepers in accessing my participants, from ethics committees, to senior managers, line managers, frontline practitioners, corporate parents and biological parents. I spent a substantial amount of time face-to-face with potential gatekeepers, discussing the research project, allaying concerns and answering questions:

We are interested in helping you with your research and have some young people and staff in mind. However, we would like to know more so that we can be informative and supportive when discussing with possible volunteers (Residential Manager)

The gatekeepers I encountered provided an appropriate level of safeguard, rather than any troublesome barriers and, as far as I was aware, no gatekeeper blocked access to young people. However as my research request filtered down through the organisational levels to the frontline staff that I needed, it became clear that the pressures of day-to-day practice restricted my access to practitioners, and therefore to participants. For example, in one local authority, the process from making initial contact with frontline practitioners (via several layers of management), to identifying a participant, and negotiating with additional gatekeepers (residential staff and parents) before arranging a first meeting simply to explain the project to the young person took three months.

The need to navigate gatekeepers does not disappear in practitioner research, but whereas external researchers have been described as powerlessly dependent on the goodwill of agencies and workers (Aldgate \& Bradley, 2004), internal researchers tend to have existing relationships with gatekeepers, may be more trusted by gatekeepers and participants, and also represent one layer of gatekeeping themselves. The process may therefore be smoothed and expedited.

Informed consent.

A related issue is that of obtaining informed consent. Notwithstanding the broader debate about whether it is possible to obtain truly informed consent in qualitative research (Buckle et al., 2010; Hadjistavropoulos \& Smythe, 2001; Rosenblatt, 1995; Wiles et al., 2007), the issue of obtaining, and maintaining, informed consent with children and young people has been a longstanding subject of debate. Historically, consent has been provided by adult gatekeepers, and children have merely 
assented to participation (Fargas-Malet et al., 2010; Morris et al., 2012; Phelan \& Kinsella, 2013). The debate has since moved forward to focus more on competency rather than chronological age for children aged under 16 (Fargas-Malet et al., 2010; Kirk, 2007; Morris et al., 2012; Wiles et al., 2007) but there is still no definitive position, especially when it comes to more vulnerable children. Furthermore, gatekeepers may misunderstand or convey inaccurate or insufficient information for the child to make truly informed decisions (Wiles et al., 2007). Hence the need for researchers to revisit and maintain consent and assent with participants throughout the research process (Morris et al., 2012; Wiles et al., 2007).

As it is possibly the most crucial element of ethical research, it was in this area that the ethical review committees requested that I make changes to my research. After the initial meeting with the young person a delay was built in to the procedure to allow the participant time and space to consider the project and to ensure that consent was provided voluntarily rather than from any desire to please or inability to decline. Yet it also made the procedure more protracted and, at times, clumsy. Often days or weeks passed before the practitioner fed back that the young person had consented, and furthermore an additional meeting needed to be scheduled in to the process to provide the young person with the equipment and materials they needed to undertake the project.

The issue of voluntary and informed consent is a big one in practitioner research. The insider role would have certainly eased the logistical problems I faced, as regular contact would better facilitate the back and forth of negotiating consent, and materials could have been distributed far more easily once informed consent was received. But the dual role poses difficulties in relation to informed consent that are not easy to resolve, such as the individual's perceptions about whether they are genuinely able to withhold their consent without any repercussions (Atkinson, 2005). Yet it could be argued that with practitioners providing a gatekeeping role, and thus being aware of the decisions of the potential participants, they may not be viewed by young people as being distinct from the consent process even in traditional academic research. This certainly does not solve the problem, but it does mean that, under these circumstances, the ethical issue of informed consent may not in fact be greater in practitioner research. 
Power.

Access and consent are related to the lack of power that children have in decision-making in their lives, and loom prominently in all research with young people. While there is unarguably a large power differential between an adult researcher and a young participant (Kirk, 2007), others maintain that participation in research in itself, by positioning children as experts, can restore power to a marginalised group (Aldridge, 2012). Selecting an appropriate method, however, is crucial in engaging young people and in helping to redress some of this imbalance (Aldridge, 2012; Phelan \& Kinsella, 2013). In this regard, participatory methods are designed to better involve children and young people directly in research and include: interviews; vignettes; role play; picture prompts; drawings (Hill, 1997) and, more recently, photography and other arts-based techniques (Clark \& Morriss, 2017; Coad, 2007; Driessnack \& Furukawa, 2012; Kolb, 2008). This power imbalance is to some extent addressed by the photoelicitation method which allows children control about what subjects are discussed (Cappello, 2005; Einarsdottir, 2005), and also gives them the time and space to process and organise their thoughts before they are asked to share them (Driessnack \& Furukawa, 2012). However, Holland, Renold, Ross, and Hillman (2010) do caution against assuming that power imbalances are equalised simply by the adoption of a participatory method.

I therefore selected my approach for its ability to involve and engage children and young people, and for them to attain at least some power in the process. Yet as Fassetta (2016, p. 701) observed in her research with young migrants "...young people often lack the means to move independently, and this may further restrict the subjects they are able to photograph" and this was true for my participants, especially for young people living in secure conditions who were excluded from participating due to my methodology. For example, one participant was keen to include old family photographs in his storyboard, but had to wait several weeks before he was given the necessary permissions to return home (more than 100 miles away) to visit his family and to retrieve them, prolonging the process. A practitioner researcher would have both the level of contact and authority necessary to provide the support and decision-making required.

Relationships and roles.

The relationship between the researcher and the participant is instrumental in conducting good qualitative research (Buckle et al., 2010; Dickson-Swift et al., 2007; Fahie, 2014). But this emphasis 
on the interpersonal also creates ethical issues in that boundaries may become blurred (Atkinson, 2005; Dickson-Swift et al., 2007) and practical issues in that researchers may be anxious about how best to build relationships with children appropriately (Punch, 2002). It can also cause research endings to become problematic, leaving the researcher with a sense of guilt (Campesino, 2007; Dickson-Swift et al., 2007; Fahie, 2014) and the participant with a sense of loss (Atkinson, 2005), ever more pertinent when conducting research with children already affected by loss, grief and disordered attachments.

If the relationship is the essence of good qualitative research, it is also at the heart of social work (Atkinson, 2005) and, as such, qualitative research is highly congruent with social work practice (Uggerhøj, 2012). But Atkinson (2005, p. 427) also warns that with this closeness comes very real dangers and that "the kind, friendly researcher can come to be seen as a potential helper - a sort of social worker who can offer support." However, many bereaved participants report finding that the research process has therapeutic and personal benefits (Buckle et al., 2010; Dyregrov, 2004; Omerov et al., 2014). Indeed, Buckle et al. (2010) argue that the distinction between research and therapeutic interviews is more prominent in the academic literature than is experienced in actuality. I would also argue that if role confusion already exists in qualitative research, then the dual role of practitioner researcher, rather than adding to the confusion might in fact help to provide some clarity by limiting the number of 'therapeutic' relationships.

My research process was designed to build up a level of relationship with young people before undertaking the research interview. I met each young person on approximately two occasions prior to the interview, and the storyboard creation provided a 'warm-up' activity to help create rapport. Yet in reality the relationships I established with my participants were artificial and superficial, formed over only two or three visits and never expected to be more than temporary. As these boundaries were clearly articulated prior to the research, I would not say that I felt a sense of guilt at ending the relationship, but I certainly found myself regretting not being in a position to follow up with my participants. For example, one young person was grieving over the loss of a pet, an animal that had been a great source of comfort to him during his difficult childhood. In our conversation we observed that although we tend to mark the death of humans and have memorials for them, we do not always do this for animals in the same way. Fighting away the tears he suggested that he would like to do something to mark the life and loss of his pet but was adamant he did not want me to talk to anyone 
who might be able to support him in this. Maybe he would not have expressed his feelings to a practitioner researcher in this way, but my sense is that it was the research method that helped him to open up, rather than our relationship. I never did find out whether he got his memorial.

Furthermore, the timing of such research is crucial (Stroebe et al., 2003). Many of the potential participants for my research indicated that they were interested in the study but did not feel that they were in a position to become involved at the present time:

We have spoken to the young person we had considered for this but she feels that she is not ready for this type of work and is looking for one to one counselling to talk about her loss initially, however, this project may be good for her to do in the future. (Residential Worker)

The right time, if ever, to take part in research about one's experiences is an individual decision that must always be respected. But as an outsider researcher I was at a distance from any personal change in circumstances that might have precipitated involvement, whereas a practitioner researcher may have been more aware about if and when it was appropriate to broach the subject again. This would minimise inappropriate requests and distress, but might maximise participation.

\section{Confidentiality, anonymity and disclosure.}

The co-existence of rapport (Coy, 2006; Dickson-Swift et al., 2007), a 'fun' methodology (Phelan \& Kinsella, 2013) and the sense of power and importance (Morris et al., 2012; Rowling, 1999) gained by participation can increase the likelihood of both intentional and unintentional disclosure through qualitative research. Thus, when conducting research of this nature with children and young people, it is essential that this is planned for and the circumstances of disclosure are clearly articulated and rearticulated to participants throughout the study.

In my research I found a level of disclosure that required little prompting and which occurred very early on in the research process. I observed in my research notes that even the simple act of sorting through the photographs the young person had taken stimulated a rich discussion about his personal experiences, as he started telling me a little about the importance behind each image:

[pointing at a photograph of a bottle of whisky] ...my Da and that were all alcoholics, my big brother's an alcoholic, so that's what that photy means...and one of my uncles nearly died with alcohol. (young person)

This level of disclosure made me feel privileged but also acted as a reminder that the methodology and context helped to facilitate disclosure. This poses potentially the greatest problem 
with practitioner research, and one that is not easily overcome. While all researchers need to clearly outline the circumstances of disclosure (such as when there is risk of imminent harm), even if a practitioner assures the participant that their information will be kept confidential outwith these rare and specified instances, it remains that what information has been heard cannot be unheard. This information may prove useful in planning therapies and interventions and may have direct benefits to participants, something that is often lacking in traditional research, but it also poses a major ethical dilemma due to the significant level of reflexivity and objectivity required to ensure that this information does not influence future decision-making for the individual in a detrimental way.

\section{Minimising Distress.}

While all research should aim to minimise distress to participants, when the research involves both vulnerable children and a topic such as death, bereavement and loss then the need, and the desire, to protect is intensified. For ethics committees the potential to cause distress remains a fundamental concern (Rosenblatt, 1995). However, emotions are inextricably linked with loss and bereavement, and their expression can be a key part of understanding people's experiences (Rowling, 1999). Studies of bereaved parents (Dyregrov, 2004; Hynson, Aroni, Bauld, \& Sawyer, 2006) have indicated that while many found talking about their losses painful, many also found the process to have benefitted them personally, and few regretted their participation. As a result, Hynson et al. (2006, p. 810) warn that we must not "...simply assume that the likely expression of negative emotions within the research process means that research is inherently insensitive or unethical."

My participants were already vulnerable because their many adverse life experiences meant that they needed to be looked after away from home, but by confronting their experiences of loss, death and separation head on I could potentially expose them to further pain and distress. Yet, as Buckle et al. (2010, p. 117) question, "are we causing or inducing pain when we ask research participants about their experience of the death of their loved one or are we bearing witness to the pain that is already there?" In my previous research (Vaswani, 2014) young people undoubtedly found it challenging, but typically seized the chance to recount their stories of loss and grief, often for the first time, with gratitude. While this gave me the confidence to proceed with the study, even temporary distress needs to be prepared for, acknowledged and managed (Omerov et al., 2014). 
I found that all of my participants expressed some difficult emotions, either verbally or through their body language. While this was to be expected, I was surprised at the strength of my desire not to intensify their pain. In our society we are often uncomfortable with observing others in distress, not least when we think we may have contributed to this distress in some way (Fahie, 2014). Witnessing a young man fighting back the tears as he talked about his losses, I found myself regularly offering him a way out of the conversation or making the decision to change the topic:

Are you alright? It's difficult to think about these things, we don't have to keep going...(interview transcript)

Whether this was the right decision, or whether the exchange would have been different if I had allowed him more time with his grief I will never know. A practitioner researcher would have ongoing contact with the participant, in which these emotions could be allowed to resurface, or which could be supported through direct intervention outside of the research process (Coy, 2006). Certainly Chan has argued that practitioner presence and expertise during research can minimise harm through better identification of distress and the provision of concurrent, rather than post-research, support (Chan, Teram, \& Shaw, 2017). Furthermore, bereavement researchers need therapists' skills in that they listen, acknowledge, do not judge (Rosenblatt, 1995) but also, because of the emotional impact of the stories they hear, they need therapists' 'safety nets' in terms of reflective practice, professional supervision, and self-care (Coy, 2006; Dickson-Swift et al., 2007). Yet if we are arguing that researchers need to be more like practitioners, then surely it would be simpler if they were practitioners?

\section{Practical arrangements.}

One unavoidable barrier, not ethical or methodological, but very much part and parcel of the reality of life, was the impact of my maternity leave seven months into the project. While the funder was flexible and extended the grant to account for my leave, I had not anticipated the length of time to get the project off the ground, and it had only just gathered momentum as I embarked on my leave. Research of this design takes time and commitment, and upon my return these relationships once again took time to rebuild as people (staff and children alike) had moved on. Furthermore, my phased return to work over several months meant that it was some time before I could offer the intensity and flexibility of my time that the project needed. Life does not stop for research projects, and while this will also be true of practitioner research, the nature of their role means that cover arrangements are more likely and the project may have been able to continue through periods of absence. 


\section{Discussion}

My research 'failed' to overcome some of the challenges that it encountered. Does this mean that my research itself is a 'failure'? Each participant received both a 'thank-you' card, voucher and hard-backed photobook of their artwork to provide 'closure' to their individual participation. But ultimately my participants, who gave their time willingly and shared their personal thoughts and experiences with honesty and bravery, have not yet had the chance to contribute collectively to the advancements in loss and bereavement practice that they might have hoped for. This outcome is disappointing for all involved.

Early reviews of this paper commented on my 'bravery' in publishing the details of an unsuccessful project and acknowledged a paucity of research papers from this perspective. Although reviewers were encouraging and supportive, their choice of words intimated to me the presence of risk, be it personal or professional. Yet it seemed to me that publication of this paper was not really a choice, but that I had a duty to my participants (and to potential research participants in the future) to ensure that no time and effort was wasted. In reflecting on my experiences, and in making this learning public, the research can also be seen as an important step in what is a shared journey, rather than simply a final outcome in itself. In this way my participants have still contributed to a wider knowledge-base, and their stories and experiences may yet help inform future improvements, not only in bereavement practice, but also in bereavement research.

As my experience has confirmed, there are clearly many challenges in conducting ethical qualitative research to a high standard. No more so than when the topic is sensitive, or the participants are vulnerable. Gaining approval to conduct research, navigating gatekeepers, and accessing participants. Ensuring that participants are fully informed and are able to freely give or withhold their consent. Designing a research method that is engaging, accessible and redresses any power differentials, but that is also meaningful and purposeful in that it will allow the research questions to be answered. Building genuine relationships that encourage disclosure but that are not exploitative, and ending them sensitively and without guilt. Hearing difficult, and often previously untold, stories in a way that does not cause participants, or researchers, any unnecessary distress. All must be successfully navigated on the route towards fruitful and ethical research. 
There are also many well-documented pitfalls of practitioner research, most often relating to rigour and quality, or specific ethical concerns. These include a lack of time, skills, capacity, support, theoretical alignment, critical distance and objectivity. Furthermore, the blend of roles between 'therapy' and 'research' can be confusing and even coercive with a large power imbalance. The wisdom of suggesting that practitioners are best placed to undertake research on sensitive topics with vulnerable participants might therefore easily be questioned (Chan et al., 2017).

To counter, I suggest that the problem lies less with practitioner research, and more with the assumption that academic research is somehow necessarily better or more ethical or more objective. If all good qualitative research is relationship-based with inevitably blurred boundaries, offers therapeutic potential but is affected by an inherent hierarchical distribution of power that cannot be easily dismantled, then the ethical criticisms levelled at practitioner research lose their uniqueness. If academics face funding shortages, capacity issues, challenges in balancing competing priorities and limited support infrastructure (Moriarty, Manthorpe, Stevens, \& Hussein, 2015), then the practical barriers are not practitioners' alone.

While familiarity and 'insider' status may be viewed as a threat to objectivity (Greene, 2014), the reality is that no researcher, no matter how experienced or how far removed, can be truly objective. Personal experiences, emotions, beliefs and knowledge (Rowling, 1999) as well as professional, social, political and cultural contexts (Uggerhøj, 2012) all constrain objectivity. No more so than in loss and bereavement research, which has the potential to resonate with both practitioners' and researchers' experiences (Rowling, 1999). Subjectivities are not necessarily a hindrance in qualitative research: participants' opinions and experiences are subjective but are often the desired object of attention in research; the relationship and shared understandings established between researcher and participant throughout the research process can be seen as a form of 'intersubjectivity' between them (Morrow, 2007). Subjectivity does of course need to be acknowledged and managed and reflexivity is therefore crucial. I tried hard to remain aware of the impact of my own experiences of loss and grief, my knowledge and understanding and my personal beliefs at all times. However, the culture of professional supervision and reflective practice with social work means that practitioners may be better placed to identify and minimise these issues. 
Of course, there are some elements of practitioner research that remain problematic and difficult to unpick. Most clearly those dilemmas relate to confidentiality and disclosure, and ensuring that the participant is clear about the purpose of the work at all times, especially if therapeutic and research boundaries are blurred. It would also be of benefit to both practice and research if methods and procedures continued to develop and improve children's understanding, engagement and participation in research, especially that which is concerned with sensitive or personally challenging topics. Yet, as my paper has shown, many of the 'challenges' of practitioner research are not unique to practitioner research and we should not discount the role of the practitioner researcher when conducting research on sensitive topics with vulnerable children.

\section{References}

Aldgate, J., \& Bradley, M. (2004). Children's experiences of short term accommodation. In V. Lewis, M. Kellett, C. Robinson, S. Fraser, \& S. Ding (Eds.), The reality of research with children and young people (pp. 67-93). London: Sage.

Aldridge, J. (2012). The participation of vulnerable children in photographic research. Visual Studies, 27(1), 48-58.

Allen, L. (2011). 'Picture this': using photo-methods in research on sexualities and schooling. Qualitative Research, 11(5), 487-504. doi:doi:10.1177/1468794111413224

Appleby, M. M. (2013). The Nature of Practitioner Research: Critical distance, power and ethics. Practitioner Research in Higher Education, 7(1), 11-21.

Atkinson, D. (2005). Research as social work: Participatory research in learning disability. British Journal of Social Work, 35(4), 425-434.

Atkinson, P., \& Delamont, S. (1993). Bread and dreams or bread and circuses? A critique of case study research in evaluation. In M. Hammersley (Ed.), Controversies in the Classroom (2nd ed.). Buckingham: Open University Press.

Bignante, E. (2010). The use of photo-elicitation in field research. Exploring Maasai representations and use of natural resources. EchoGéo(11).

Brodzinsky, D. (2009). The experience of sibling loss in the adjustment of foster and adopted children. In D. N. Silverstein \& S. L. Smith (Eds.), Siblings in adoption and foster care: traumatic separations and honored connections (pp. 45-56). Connecticut: Praeger.

Brydon-Miller, M., \& Maguire, P. (2009). Participatory action research: Contributions to the development of practitioner inquiry in education. Educational Action Research, 17(1), 79-93.

Buckle, J. L., Dwyer, S. C., \& Jackson, M. (2010). Qualitative bereavement research: incongruity between the perspectives of participants and research ethics boards. International Journal of Social Research Methodology, 13(2), 111-125. doi:10.1080/13645570902767918

Campesino, M. (2007). Homicide Bereavement. Qualitative Inquiry, 13(4), 541-553. doi:doi:10.1177/1077800406297677

Cappello, M. (2005). Photo Interviews: Eliciting Data through Conversations with Children. Field Methods, 17, 170182. doi:10.1177/1525822X05274553

Chan, T. M. S., Teram, E., \& Shaw, I. (2017). Balancing Methodological Rigor and the Needs of Research Participants:A Debate on Alternative Approaches to Sensitive Research. Qualitative Health Research, 27(2), 260-270. doi:10.1177/1049732315605272

Clark, A., \& Morriss, L. (2017). The use of visual methodologies in social work research over the last decade: A narrative review and some questions for the future. Qualitative Social Work, 16, 29-43. doi:10.1177/1473325015601205

Close, H. (2007). The use of photography as a qualitative research tool. Nurse Researcher, 15(1), 27-36. doi:10.7748/nr2007.10.15.1.27.c6052

Coad, J. (2007). Using art-based techniques in engaging children and young people in health care consultations and/or research. Journal of Research in Nursing, 12, 487-497. doi:10.1177/1744987107081250

Collier, J. (1957). Photography in Anthropology: A Report on Two Experiments. American Anthropologist, 59, 843859. doi:10.1525/aa.1957.59.5.02a00100

Connolly, K., \& Reilly, R. C. (2007). Emergent Issues When Researching Trauma. Qualitative Inquiry, 13(4), 522540. doi:doi:10.1177/1077800406297678

Cook, A. S. (1995). Ethical issues in bereavement research: An overview. Death Studies, 19(2), 103-122. 
Courtney, A. (2000). Loss and Grief in Adoption: The Impact of Contact. Adoption \& Fostering, 24, 33-44. doi:10.1177/030857590002400206

Coy, M. (2006). This Morning I'm A Researcher, This Afternoon I'm An Outreach Worker: Ethical Dilemmas in Practitioner Research. International Journal of Social Research Methodology, 9(5), 419-431. doi:10.1080/13645570601076785

Dadds, M. (1998). Supporting practitioner research: a challenge. Educational Action Research, 6(1), 39-52. doi:10.1080/09650799800200049

Dickson-Swift, V., James, E. L., Kippen, S., \& Liamputtong, P. (2007). Doing sensitive research: what challenges do qualitative researchers face? Qualitative Research, 7(3), 327-353. doi:doi:10.1177/1468794107078515

Driessnack, M., \& Furukawa, R. (2012). Arts-based data collection techniques used in child research. Journal for specialists in pediatric nursing : JSPN, 17, 3-9. doi:10.1111/j.1744-6155.2011.00304.x

Dwyer, S. C., \& Buckle, J. L. (2009). The Space Between: On Being an Insider-Outsider in Qualitative Research. International Journal of Qualitative Methods, 8(1), 54-63. doi:doi:10.1177/160940690900800105

Dyregrov, K. (2004). Bereaved parents' experience of research participation. Social science \& medicine, 58(2), 391-400. doi:http://dx.doi.org/10.1016/S0277-9536(03)00205-3

Einarsdottir, J. (2005). Playschool in pictures: children's photographs as a research method. Early Child Development and Care, 175, 523-541. doi:10.1080/03004430500131320

Emmel, N., Hughes, K., Greenhalgh, J., \& Sales, A. (2007). Accessing Socially Excluded People — Trust and the Gatekeeper in the Researcher-Participant Relationship. Sociological Research Online, 12(2), emmel.

Fahie, D. (2014). Doing sensitive research sensitively: ethical and methodological issues in researching workplace bullying. International Journal of Qualitative Methods, 13(1), 19-36.

Fargas-Malet, M., McSherry, D., Larkin, E., \& Robinson, C. (2010). research with children: methodological issues and innovative techniques. Journal of Early Childhood Research, 8, 175-192. doi:10.1177/1476718X09345412

Fassetta, G. (2016). Using photography in research with young migrants: addressing questions of visibility, movement and personal spaces. Children's Geographies, 14(6), 701-715. doi:10.1080/14733285.2016.1190811

Greene, M. J. (2014). On the inside looking in: Methodological insights and challenges in conducting qualitative insider research. The qualitative report, 19(29), 1-13

Groundwater-Smith, S., \& Mockler, N. (2007). Ethics in practitioner research: an issue of quality. Research Papers in Education, 22(2), 199-211. doi:10.1080/02671520701296171

Hadjistavropoulos, T., \& Smythe, W. E. (2001). Elements of Risk in Qualitative Research. Ethics \& Behavior, 11(2), 163-174. doi:10.1207/S15327019EB1102_4

Hare, A. D., \& Bullock, R. (2006). Dispelling Misconceptions about Looked after Children. Adoption \& Fostering, 30(4), 26-35. doi:doi:10.1177/030857590603000405

Harper, D. (2002). Talking about pictures: A case for photo elicitation. Visual Studies, 17(1), 13-26. doi:10.1080/14725860220137345

Hill, M. (1997). Participatory research with children. Child \& Family Social Work, 2(3), 171-183. doi:10.1046/j.13652206.1997.00056.x

Hodkinson, P. (2005). 'Insider Research' in the Study of Youth Cultures. Journal of Youth Studies, 8(2), 131-149. doi:10.1080/13676260500149238

Holland, S., Renold, E., Ross, N. J., \& Hillman, A. (2010). Power, agency and participatory agendas: A critical exploration of young people's engagement in participative qualitative research. Childhood, 17(3), 360375. doi:10.1177/0907568210369310

Horowitz, J. A., Ladden, M. D., \& Moriarty, H. J. (2002). Methodological Challenges in Research with Vulnerable Families. Journal of Family Nursing, 8(4), 315-333. doi:doi:10.1177/107484002237510

Hynson, J., Aroni, R., Bauld, C., \& Sawyer, S. (2006). Research with bereaved parents: a question of how not why Palliative medicine, 20(8), 805-811.

IRISS. (2013). PROP (Practitioner Research: Older People). Retrieved from Glasgow: http://blogs.iriss.org.uk/prop/files/2013/01/PROP-Briefing-Paper-1-Lessons-from-PRPs-December20122.pdf

Joubert, L., \& Hocking, A. (2015). Academic Practitioner Partnerships: A Model for Collaborative Practice Research in Social Work. Australian Social Work, 68(3), 352-363. doi:10.1080/0312407X.2015.1045533

Kirk, S. (2007). Methodological and ethical issues in conducting qualitative research with children and young people: A literature review. International Journal of Nursing Studies, 44(7), 1250-1260. doi:http://dx.doi.org/10.1016/j.ijnurstu.2006.08.015

Kolb, B. (2008). Involving, Sharing, Analysing-Potential of the Participatory Photo Interview. Forum Qualitative Sozialforschung / Forum: Qualitative Social Research, 9.

Mitchell, F., Lunt, N., \& Shaw, I. (2010). Practitioner research in social work: a knowledge review. Evidence \& Policy: A Journal of Research, Debate and Practice, 6(1), 7-31. doi:10.1332/174426410X482971

Moriarty, J., Manthorpe, J., Stevens, M., \& Hussein, S. (2015). Educators or Researchers? Barriers and Facilitators to Undertaking Research among UK Social Work Academics. The British Journal of Social Work, 45(6), 1659-1677. doi:10.1093/bjsw/bcu077

Morris, A., Hegarty, K., \& Humphreys, C. (2012). Ethical and safe: Research with children about domestic violence. Research Ethics, 8, 125-139. doi:10.1177/1747016112445420 
Morrow, S. L. (2007). Qualitative Research in Counseling Psychology. The Counseling Psychologist, 35(2), 209235. doi:10.1177/0011000006286990

Newman, E., Risch, E., \& Kassam-Adams, N. (2006). Ethical issues in trauma-related research: A review. Journal of Empirical Research on Human Research Ethics, 1(3), 29-46.

Omerov, P., Steineck, G., Dyregrov, K., Runeson, B., \& Nyberg, U. (2014). The ethics of doing nothing. Suicidebereavement and research: ethical and methodological considerations. Psychological medicine, 44(16), 3409-3420.

Pain, H. (2011). Practice research: what it is and its place in the social work profession. European Journal of Social Work, 14(4), 545-562. doi:10.1080/13691457.2010.490062

Patton, M. Q. (2002). Two Decades of Developments in Qualitative Inquiry. Qualitative Social Work, 1(3), 261-283. doi:doi:10.1177/1473325002001003636

Payne, G. (2011). Setting Up Sociological Research. In M. Williams \& P. Vogt (Eds.), The Sage Handbook of Innovation in Social Research Methods (pp. 44-61). London: Sage Publications Ltd.

Phelan, S. K., \& Kinsella, E. A. (2013). Picture This ... Safety, Dignity, and Voice-Ethical Research With Children. Qualitative Inquiry, 19(2), 81-90. doi:doi:10.1177/1077800412462987

Powell, M. A., \& Smith, A. B. (2009). Children's Participation Rights in Research. Childhood, 16, $124-142$. doi:10.1177/0907568208101694

Pritchard, I. A. (2002). Travelers and Trolls: Practitioner Research and Institutional Review Boards. Educational Researcher, 31(3), 3-13. doi:doi:10.3102/0013189X031003003

Punch, S. (2002). Research with Children: The Same or Different from Research with Adults? Childhood, 9, 321341. doi:10.1177/0907568202009003005

Reid, W. J. (1994). The Empirical Practice Movement. Social Service Review, 68(2), 165-184. doi:10.1086/604045

Ribbens McCarthy, J. (2005). The impact of bereavement and loss on young people | JRF, York.

Riches, G., \& Dawson, P. (1998). Lost Children, Living Memories: The Role Of Photographs In Processes Of Grief And Adjustment Among Bereaved Parent. Death Studies, 22(2), 121-140. doi:10.1080/074811898201632

Rosenblatt, P. C. (1995). Ethics of qualitative interviewing with grieving families. Death Studies, 19(2), 139-155. doi:10.1080/07481189508252721

Rowling, L. (1999). Being in, being out, being with: Affect and the role of the qualitative researcher in loss and grief research. Mortality, 4(2), 167-181. doi:10.1080/713685968

Shaw, C., Brady, L.-M., \& Davey, C. (2011). Guidelines for research with children and young people. London: National Children's Bureau Research Centre.

Shaw, I. (2005). Practitioner Research: Evidence or Critique? The British Journal of Social Work, 35(8), 1231-1248. doi:10.1093/bjsw/bch223

Shaw, I., \& Lunt, N. (2012). Constructing practitioner research. Social Work Research, 36(3), $197-208$. doi:10.1093/swr/svs013

Stoecker, R. (1999). Are Academics Irrelevant? American Behavioral Scientist, 42(5), $840-854$. doi:doi:10.1177/00027649921954561

Stroebe, M., Stroebe, W., \& Schut, H. (2003). Bereavement research: Methodological issues and ethical concerns. Palliative medicine, 17(3), 235-240.

Uggerhøj, L. (2012). Theorizing practice research in social work. Social Work and Social Sciences Review, 15(1), 49-73.

Vaswani, N. (2014). The ripples of death: Exploring the bereavement experiences and mental health of young men in custody. The Howard Journal of Crime and Justice, 53(4), 341-359.

Vaswani, N. (2015). A catalogue of losses : implications for the care and reintegration of young men in custody. Prison Service Journal, 220, 26-35.

Whiting, L. S. (2015). Reflecting on the use of photo elicitation with children. Nurse Researcher, 22(3), 13-17. doi:10.7748/nr.22.3.13.e1283

Wiles, R., Crow, G., Charles, V., \& Heath, S. (2007). Informed Consent and the Research Process: Following Rules or Striking Balances? Sociological Research Online, 12(2), wiles.

Woodthorpe, K. (2009). Reflecting on death: The emotionality of the research encounter. Mortality, 14(1), 70-86. doi:10.1080/13576270802591228 